\title{
REPRESENTAÇÃO TERMINOLÓGICA DA POPULAÇÃO NEGRA EM TESAUROS
}

\section{TERMINOLOGICAL REPRESENTATION OF THE BLACK POPULATION IN TESAUROS}

\author{
Andréia dos Santosa \\ Amabile Costab \\ Camila Monteiro de Barrosc \\ Luciane Paula Vitald
}

\begin{abstract}
RESUMO
Introdução: $O$ presente trabalho investiga a representação terminológica sobre a população negra em tesauros de diferentes áreas do conhecimento. O referencial teórico está voltado à interpretação da dimensão social que abarca as práticas da organização do conhecimento. Os pesquisados da área de OC tem repensado e trazido para discussão processos de representação mais plurais e igualitários, com posicionamento ético e reflexivo. Objetivos: Objetiva-se analisar quais são as relações conceituais atribuídas aos termos 'negro' e 'afro-brasileiro' em tesauros de diferentes áreas do conhecimento. Metodologia: A pesquisa está caracterizada como exploratória e bibliográfica. Foram analisados os termos "afro-brasileiro" e "negro" nos seguintes tesauros: Ciência da Informação, Educação, Estudos de Gênero sobre Mulheres, Folclore e Cultura Popular, Justiça Militar da União, Objetos do Patrimônio Cultural nos Museus Brasileiros, e UNESCO. Resultados: Constatou-se que os tesauros analisados fortalecem a imagem do negro associada a termos pejorativos em suas representações. Conclusões: Os SOCs são ferramentas utilizadas para a recuperação da informação, contudo, percebe-se que a estrutura desses instrumentos refletem a realidade na qual esses sistemas estão inseridos. Percebe-se que pesquisadores da área de organização do conhecimento tem repensado e trazido discussões com posicionamento ético e reflexivo.
\end{abstract}

\footnotetext{
a Mestra pelo Programa de Pós-Graduação em Ciência da Informação da Universidade Federal de Santa Catarina (UFSC). Email: andreia.santos@ifc.edu.br

b Mestranda no Programa de Pós-Graduação em Ciência da Informação da Universidade Federal de Santa Catarina (UFSC). Email: amabilecosta.m@gmail.com

c Professora do Departamento de Ciência da Informação e do Programa de Pós-Graduação em Ciência da Informação da UFSC. Doutora e Mestre em Ciência da Informação pela Universidade Federal de Santa Catarina. Email: camila.c.m.b@ufsc.br

d Professora no Departamento de Ciência da Informação da Universidade Federal de Santa Catarina. Doutorado e Mestrado em Ciência da Informação (UFSC). Email: luciane.vital@ufsc.br
} 
Descritores: Sistema de Organização do Conhecimento. Tesauros. População Negra.

\section{INTRODUÇÃO}

A informação, bem como a preocupação com seu registro, preservação e disseminação, acompanha o comportamento humano desde a antiguidade. Já na contemporaneidade, sobretudo a partir da segunda metade do século $X X$, ocorreu um crescimento exponencial na produção informacional, nos meios de produção do conhecimento e nas atividades de pesquisa científica, que resultou no atual cenário social que tem na produção e materialização do conhecimento a matéria-prima de seu desenvolvimento (SOUSA; ALBUQUERQUE, 2015).

$O$ expressivo volume informacional produzido e acumulado desencadeou uma soma de esforços técnicos, científicos e conceituais que se dedicam a organização e a posterior representação e recuperação do conhecimento registrado, como subsídio à perpetuação da memória social e à construção de novos conhecimentos. Nessa perspectiva, despontou a organização e representação do conhecimento $(\mathrm{ORC})$ como área científica voltada ao estudo dessas questões (LIMA; ALVARES, 2012).

$\mathrm{Na}$ tentativa de consolidar as bases teóricas e metodológicas da área, diversos autores sentiram a necessidade de formular conceitos a respeito da Organização do Conhecimento. Na perspectiva de Esteban Navarro (1996, p. 97-98, tradução nossa), a organização do conhecimento:

[...] estuda os fundamentos teóricos do tratamento e da recuperação da informação, construção, manutenção, uso e avaliação dos instrumentos lógico-linguísticos mais adequados para controlar os processos de representação, classificação, ordenação e armazenamento do conteúdo informativo dos documentos com a finalidade de permitir sua recuperação e comunicação.

Miranda (1999) e Barité (2001) entendem que esta se constitui em uma disciplina científica, inter e transdisciplinar, que trata do desenvolvimento de técnicas para construção, gestão e uso, avaliação de classificações científicas, taxonomias, nomenclatura e linguagens documentais, cujo objetivo é gerir e difundir em nível de excelência a informação no âmbito dos arquivos, bibliotecas, centros de informação/documentação e museus. Já para Dahlberg (2006 apud 
CARLAN, 2010, p. 25), a:

Organização do Conhecimento é a ciência que ordena a estruturação e sistematização dos conceitos, de acordo com suas características, que podem ser definidas como elementos de herança do objeto, e a aplicação dos conceitos e classes dos conceitos ordenados pela indicação de valores, dos referentes conteúdo dos objetos ou assuntos.

Assim, de forma ampla, é possível observar que os estudos acerca da ORC tendem à interpretação de que a mesma se configura em uma disciplina científica que desenvolve técnicas, instrumentos e processos para o tratamento e a recuperação da informação. Atualmente, contudo, dado o impacto da inserção tecnológica e informacional e em decorrência da forte influência da globalização, que aproximou múltiplas perspectivas econômicas, sociais e culturais, torna-se primordial trazer à luz discussões e reflexões acerca do posicionamento ético e da dimensão social que permeia as práticas da ORC (GUIMARÃES; PINHO, 2006).

Nesse sentido, Martínez-Ávila et al. (2015) e Ortolan et al. (2017) afirmam que a ORC tem desenvolvido pesquisas referentes à construção de conceitos relacionados a aspectos sociais e representação ética. Pinho (2010), por sua vez, diz que as atividades da ORC devem perpassar um 'fazer técnico' e voltar suas preocupações cada vez mais às dimensões sociais, em que o produto e o processo da representação do conhecimento dedicam-se à utilidade e à adequação para determinada comunidade ou grupo-alvo.

A ORC pode contribuir para o entendimento de como está estruturada a linguagem de uma comunidade discursiva (PINHO; NASCIMENTO; MARINHO, 2013). Assim, considerando que o conhecimento é uma construção social (MIRANDA, 2007), e que, no contexto brasileiro, o racismo não pode ser considerado apenas uma atitude individual, mas um comportamento estrutural, que se manifesta social, política, econômica e culturalmente (CARDOSO, PINTO, 2018), postula-se por sistemas de organização do conhecimento que contemplem possibilidades de representar os conteúdos acumulados ao longo do tempo por uma história plural e multicultural. Uma vez que esses sistemas refletem a realidade em que estão inseridos (MAl, 2004), não sendo dotados de neutralidade, refletindo os valores dominantes de uma sociedade (OLSON, 
2002).

Nesse sentido, o processo de análise e construção de uma estrutura conceitual que formará um sistema de organização do conhecimento é desenvolvido em consonância com os contextos sócio, político e econômico nos quais estão inseridos. Dessa forma, ao perceber que "o Brasil é um país onde existe preconceito e a discriminação de raça e cor" (CARDOSO, 2011, p.13), as ferramentas que tratam da representação terminológica da produção informacional a respeito da população negra não estarão privadas das impressões do racismo. Além disso, acredita-se que a organização e representação terminológica a respeito da população negra caracteriza-se "como processo de exclusão que elege uma língua universal e exprime um conhecimento desvinculado das necessidades de informação específica que o usuário busca" (AQUINO; SANTANA, 2013 p. 24). Isso conduz à reflexão que a atividade da ORC decorre de um fazer técnico para "uma atividade intelectual que exige por parte do profissional uma postura consciente e crítica, além de ser pleno conhecedor dos aspectos históricos e sociais que envolvem 0 conhecimento registrado e socializado" (GUIMARÃES; PINHO, 2006, p. 2).

Para que se torne possível atingir o propósito da recuperação da informação, a ORC estuda e desenvolve sistemas com o objetivo de organizar, representar e recuperar conteúdos informacionais, os chamados sistemas de organização do conhecimento (SOCs). Dentre os diferentes tipos de SOCs, estão os tesauros, que, na visão de Sales e Café (2009, p. 102) são:

\begin{abstract}
Vocabulários controlados formados por termos-descritores semanticamente relacionados, e atuam como instrumentos de controle terminológico. Os tesauros podem estar estruturados hierarquicamente (gênero-espécie e todo-parte) e associativamente (aproximação semântica), e são utilizados principalmente para indexar e recuperar informações por meio de seu conteúdo.
\end{abstract}

$\mathrm{Na}$ tentativa de investigar a representação terminológica a respeito da população negra no Brasil, bem como propor a reflexão da dimensão social e ética que permeia as atividades da ORC, o objetivo do presente artigo é analisar quais são as relações conceituais atribuídas aos termos 'negro' e 'afro-brasileiro' em tesauros de diferentes áreas do conhecimento.

A fim de responder o objetivo geral do trabalho, foram elaborados alguns 
objetivos específicos, a saber: a) caracterizar os tesauros que compõem 0 estudo; b) analisar os termos delimitados e as relações semânticas apresentadas no SOC e c) apresentar e discutir os resultados a partir da sua comparação com a literatura investigada.

\section{SISTEMAS DE ORGANIZAÇÃO DO CONHECIMENTO}

A Organização e Representação do Conhecimento "tem o papel de padronizar a terminologia adotada para organização e recuperação da informação, ao delimitar o uso de termos e definir conceitos e relações de alguma área do conhecimento" (BRASCHER; CARLAN, 2010, p. 149). Por meio dos seus produtos, os chamados sistemas de organização do conhecimento (SOCs), empregam a padronização terminológica para orientar a atividade de indexação da informação e possibilitar sua recuperação pelos usuários.

Os SOCs "são esquemas que organizam, gerenciam e recuperam informação e a base dos modernos sistemas são termos e indicações de relacionamentos entre eles" (BRASCHER; CARLAN, 2010, p. 151). A construção dos SOCs envolve o processo (comum entre esses sistemas) de seleção de termos, conceitos e classificações terminológicas; determinação de categorias, classes, subclasses e a especificação de características, propriedades ou atributos (CARLAN, 2010).

Os SOCs são usados como instrumentos intermediários e desempenham a comunicação entre sistema e usuário, qualificando a resposta a uma busca informacional (CINTRA et al., 2002). Esses sistemas tencionam eliminar a ambiguidade, controlar o uso de termos sinônimos ou equivalentes e estabelecer relações semânticas entre os conceitos. Existem vários sistemas que se diferenciam pela sua estrutura, de simples até multidimensional (CARLAN; MEDEIROS, 2011).

Em um SOC existem relações conceituais, conforme Cintra et al. (2002), podem ser: hierárquicas, associativas e de equivalência (sinônimos). As relações hierárquicas são do tipo gênero-espécie ou partitiva. Na relação hierárquica gênero-espécie, a espécie herda os atributos do gênero e apresenta mais alguma(s) característica(s) que a diferencia das demais espécies do mesmo 
gênero (CINTRA et al. 2002). Nesse caso, o gênero engloba o conjunto das características comuns das espécies. Em outras palavras, a espécie "é um" ou "é um tipo" do gênero, por exemplo: "navio" e "canoa" são espécies (tipos de) "meio de transporte aquático".

As relações partitivas se referem a uma relação todo-parte, sendo que as partes seriam componentes do conjunto de características do todo, por exemplo: "porta" e "janela" são partes de "casa". Já as relações associativas são definidas por Cintra et al. (2002) como todas aquelas relações conceituais que não são hierárquicas, não sendo possível definir um número de tipos de relações associativas.

Os SOCs são considerados esquemas de conceitos estruturados semanticamente que contemplam termos, definições, relacionamentos e propriedades dos conceitos e que, por meio de esquemas, organizam e representam o conhecimento (BRASCHER; CARLAN, 2010), para Dahlberg (1978) o conceito é o conhecimento de um determinado assunto representado na forma verbal. Os conceitos podem ser apresentados como conceito individual e geral. Quando falamos em conceito individual evidenciamos que "é aquele que se refere a algo único, diferente dos demais, constituindo uma unidade inconfundível" (CARLAN, 2010, p. 80). Já o conceito geral "se refere a uma multiplicidade de coisas" (CARLAN, 2010, p. 80).

De acordo com Dahlberg (1978), o conceito tem também como características a intensão e a extensão. A intensão é a soma total das características específicas, ou seja, está relacionada ao quão específico é o conceito. Já a extensão do conceito "pode ser entendida como a soma dos conceitos mais específicos para os quais a intensão é verdadeira" (CARLAN, 2010, p. 81), ou seja, a abrangência do conceito. Vale ressaltar que se trata de relações conceituais, portanto, tais características são sempre relativas ao domínio em que o conceito está sendo analisado.

Como já citado, existem diferentes SOCs, como exemplo, sistema de classificação, ontologias, taxonomias e tesauros. Para esse artigo, analisaremos o tesauro que "é considerado o instrumento de controle terminológico eficaz para a organização do conhecimento e importante ferramenta no tratamento e 
recuperação da informação" (CARLAN, 2010, p. 40).

Em dado domínio de conhecimento, a definição das relações conceituais vai além da noção estrutura pois incorre no recorte semântico, na limitação representacional dos significados e, portanto, reflete certos movimentos classificatórios sobre a própria cultura ali representada.

\subsection{TESAUROS}

Os tesauros são considerados "Instrumentos de controle terminológico, utilizados em sistemas de informação para traduzir a linguagem dos documentos, dos indexadores e dos pesquisadores numa linguagem controlada, usada na indexação e na recuperação das informações" (BRASCHER; CARLAN, 2010, p. 158). Na construção desse instrumento é "estabelecido um controle do vocabulário visando com que cada conceito seja expresso por um único e inequívoco termo ou descritor" (LAAN; FERREIRA, 2010, p. 5).

Esse tipo de SOC apresenta algumas especificidades, como por exemplo, atende a uma área específica do conhecimento, podem ser macrotesauros (conceitos amplos) ou microtesauros (conceitos específicos), a abrangência pode ser multidisciplinar ou específica (BRASCHER; CARLAN, 2010).

As finalidades do tesauro são:

a) controlar os termos usados na indexação mediante um instrumento que traduza a linguagem natural dos autores, usuários e indexadores, para uma linguagem mais controlada; b) uniformizar, mediante esta linguagem documentária, os procedimentos de indexação de profissionais em uma instituição ou numa rede cooperativa; c) limitar o número de termos necessários à explicitação dos conceitos expostos pelos autores de uma área; d) auxiliar a tarefa de recuperação da informação, fornecendo termos adequados para a estratégia de busca (IBICT, 1984, p. 1-2).

A estrutura de um tesauro deve ser realizada a partir de conceitos que serão sistematizados estabelecendo uma rede de relações (LAAN; FERREIRA, 2010). O tesauro apresenta relações semânticas, essas relações "são estabelecidas por meio da análise das características ou propriedades dos conceitos, as quais permitem identificar diferenças e semelhanças que evidenciam determinados tipos de relacionamentos" (CAFÉ; BRASCHER, 2011, 
p. 25). As relações conceituais conhecidas são aquelas apresentadas na seção anterior.

Em sua estrutura própria, as relações conceituais existentes no tesauro podem ser representadas das seguintes formas: quando há uma relação de equivalência, o termo descritor é sinalizado por "USE" e o termo não descritor como "usado para" (UP). Para estabelecer as relações hierárquicas, utiliza-se TG para termo geral e TE para termos específicos. Quando os termos apresentam relações associativas, emprega-se TR para termo relacionado. Além disso, as notas explicativas (NE) são usadas para conceituar ou detalhar um determinado termo. (PINHEIRO; FERREZ, 2014).

Para auxiliar na elaboração dos tesauros existem duas normas, a ISO 25964-1 e a ANSI/NISO Z39.19 - 2005. A norma ISO 25964-1, é um padrão internacional para tesauros publicados em duas partes, a primeira parte publicada em 2011 e dispõem de informações relacionadas ao desenvolvimento de um tesauro, incentiva a interoperabilidade de rede, modelos de dados e um esquema XML. A segunda parte foi publicada em 2013 e apresenta dicionários de sinônimos e outros tipos de vocabulários que são comumente usados para recuperação da informação (ISO, 2011). A segunda norma, ANSI/NISO Z39.192005, está disponível na Web e é composta por diretrizes para o conteúdo, exibição, construção, teste, manutenção e gerenciamento de vocabulários controlados (NISO, 2005).

Os tesauros estão vigentes e auxiliam na recuperação da informação e na organização da informação e do conhecimento de uma determinada área. Geralmente, são construídos por um coletivo, para a estruturação das informações, definição dos conceitos e das relações estabelecidas dentro dessa ferramenta.

\section{MÉTODO}

A presente pesquisa se caracteriza como exploratória e bibliográfica. Exploratória, pois, na visão de Cervo e Bevian (2002, p. 69), este tipo de pesquisa "realiza descrições precisas da situação e quer descobrir as relações existentes entre os elementos componentes da mesma." É bibliográfica pois 
busca explicar um problema a partir de um referencial teórico (CERVO; BEVIAN, 2002), nesse caso, a partir da análise dos tesauros.

As etapas de execução do trabalho consistiram em:

a) levantamento dos tesauros a serem analisados, a partir de uma busca no Google, considerando os seguintes critérios: tesauro disponível na íntegra via web, desenvolvido por instituição reconhecida nacionalmente, escolha de tesauros de diferentes áreas do conhecimento. No quadro 1 estão listados os sete tesauros selecionados para a análise:

Quadro 1 - Tesauros selecionados para a pesquisa

\begin{tabular}{|c|c|c|}
\hline Título & Instituição & $\begin{array}{l}\text { Ano de } \\
\text { criação }\end{array}$ \\
\hline Tesauro Brasileiro da Educação & $\begin{array}{l}\text { Instituto Nacional de Estudos e } \\
\text { Pesquisas Educacionais Anísio } \\
\text { Teixeira }\end{array}$ & 1980 \\
\hline Tesauro da Ciência da Informação & $\begin{array}{c}\text { Instituto Brasileiro de Informação em } \\
\text { Ciência e Tecnologia }\end{array}$ & 2014 \\
\hline Tesauro da Justiça Militar da União & Superior Tribunal Militar & 2018 \\
\hline Tesauro de la UNESCO & $\begin{array}{c}\text { Organização das Nações Unidas para } \\
\text { a Educação, a Ciência e a Cultura }\end{array}$ & 1977 \\
\hline $\begin{array}{c}\text { Tesauro de Objetos do Patrimônio } \\
\text { Cultural nos Museus Brasileiros }\end{array}$ & $\begin{array}{l}\text { Museu Histórico da Cidade do Rio de } \\
\text { Janeiro }\end{array}$ & 2014 \\
\hline $\begin{array}{c}\text { Tesauro do Folclore e Cultura } \\
\text { Popular Brasileira }\end{array}$ & $\begin{array}{c}\text { Instituto do Patrimônio Histórico e } \\
\text { Artístico Nacional }\end{array}$ & 2004 \\
\hline $\begin{array}{l}\text { Tesauro para Estudos de } \\
\text { Gênero e Sobre Mulheres }\end{array}$ & Fundação Carlos Chagas & 1998 \\
\hline
\end{tabular}

Fonte: Dados da pesquisa (2018)

b) consulta dos termos nos tesauros: em cada tesauro foi realizada a pesquisa dos termos: "negro" e "afro-brasileiro". Além disso, na intenção de ampliar a possibilidade de resultados, optou-se por incluir na análise outros termos recuperados nas buscas: termos compostos, como "aluno negro"; termos de outras categorias gramaticais (gênero - masculino ou feminino, número - singular ou plural, grau aumentativo ou diminutivo), como "mulheres negras" e "negrinho"; variações dos termos como "nego".

c) análise das relações conceituais apresentadas: os termos 
recuperados foram analisados quantitativamente, a partir da ocorrência dos termos, e qualitativamente, por meio da estrutura semântica apresentada. No total, foram analisados 18 termos conforme apresentado a seguir.

\section{RESULTADOS E DISCUSSÕES}

O quadro 2 apresenta o resultado quantitativo dos tesauros que possuíam os termos pesquisados, os resultados serão discutidos a partir da comparação dos resultados encontrados com a literatura.

Quadro 2 - Tesauros que possuem o termo "negro" e "afro-brasileiro"

\begin{tabular}{|c|c|c|}
\hline Tesauro & $\begin{array}{c}\text { Termo } \\
\text { "Negro” }\end{array}$ & $\begin{array}{c}\text { Termo “Afro- } \\
\text { brasileiro" }\end{array}$ \\
\hline Tesauro Brasileiro da Educação & Sim & Sim \\
\hline Tesauro da Ciência da Informação & Não & Não \\
\hline Tesauro da Justiça Militar da União & Não & Sim \\
\hline $\begin{array}{c}\text { Tesauro de la UNESCO } \\
\text { nos Museus Brasileiros }\end{array}$ & Sim & Sim \\
\hline $\begin{array}{c}\text { Tesauro de Objetos do Patrimônio Cultural } \\
\text { Brasileira }\end{array}$ & Não & Sim \\
\hline $\begin{array}{c}\text { Tesauro para Estudos de Gênero sobre } \\
\text { Mulheres }\end{array}$ & Sim & \\
\hline
\end{tabular}

Fonte: Dados da pesquisa (2018).

Assim, constata-se que, dos sete tesauros analisados, quatro deles apresentam os termos pesquisados.

O quadro 3 apresenta a estrutura e o contexto dos termos pesquisados nos tesauros, as notas explicativas (NE), as relações hierárquicas gêneroespécie (TG/TE), as relações associativas (TR) e grupo de assunto (GA), esse último sendo específico do Tesauro para Estudos de Gênero sobre Mulheres. Não foram observadas relações hierárquicas partitivas. 
Quadro 3 - Representação dos termos nos tesauros

\begin{tabular}{|c|c|c|}
\hline \multirow{2}{*}{ Tesauro } & \multicolumn{2}{|c|}{ Nota explicativa e estrutura de termos } \\
\hline & Afro-brasileiro & Negro \\
\hline \multirow[t]{3}{*}{$\begin{array}{l}\text { Tesauro } \\
\text { Brasileiro da } \\
\text { Educação }\end{array}$} & $\begin{array}{l}\text { Termo: Afro- } \\
\text { brasileiros } \\
\text { NE: Não encontrado } \\
\text { GA: Não encontrado } \\
\text { TG: Afro-americanos } \\
\text { TE: Não encontrado } \\
\text { TR: Não encontrado }\end{array}$ & $\begin{array}{l}\text { Termo: Aluno negro } \\
\text { NE: Não encontrado } \\
\text { GA: Não encontrado } \\
\text { TG: Alunos (condições biopsíquicas) } \\
\text { TE: Não encontrado } \\
\text { TR: Não encontrado }\end{array}$ \\
\hline & $\begin{array}{l}\text { Termo: Cultura afro- } \\
\text { brasileira } \\
\text { NE: Não encontrado } \\
\text { GA: Não encontrado } \\
\text { TG: Não encontrado } \\
\text { TE: Não encontrado } \\
\text { TR: Raízes da } \\
\text { educação brasileira }\end{array}$ & $\begin{array}{l}\text { Termo: Movimento negro } \\
\text { NE: É um processo social que visa à } \\
\text { conscientização da necessidade de } \\
\text { assumir uma identidade negra, baseada na } \\
\text { valorização da cultura negra e de suas } \\
\text { raízes africanas... O movimento negro, no } \\
\text { campo da educação, reivindica o reforço } \\
\text { da identidade da criança negra, mas sem } \\
\text { esquecer que está se constrói juntamente } \\
\text { com outras crianças que não são negras, } \\
\text { mas que também são brasileiras (Gomes, } \\
\text { A.B. Sousa. O movimento negro e a } \\
\text { pedagogia interétnica. Rev.linguagem, } \\
\text { educação e sociedade, Teresina, v.5, n.5, } \\
\text { p.50-58, 2000). } \\
\text { GA: não encontrado } \\
\text { TG: Movimentos sociais } \\
\text { TE: não encontrado } \\
\text { TR: Não encontrado }\end{array}$ \\
\hline & & $\begin{array}{l}\text { Termo: Professor negro } \\
\text { NE: É aquele que herdou geneticamente } \\
\text { determinados traços, especialmente a cor } \\
\text { da pele. Mas sob o aspecto sócio-cultural é } \\
\text { aquele a quem se aplicam determinadas } \\
\text { categorias construídas historicamente } \\
\text { desde a colonização do Brasil. "Por isto, } \\
\text { na sociedade atual, a cor da pele } \\
\text { determina posições sociais, herdadas de } \\
\text { concepções raciológicas que imputaram ao } \\
\text { negro características físicas e } \\
\text { comportamentos sob uma ótica vil e } \\
\text { pejorativa" (Coelho, Vilma Baía. O } \\
\text { professor negro na Universidade. }\end{array}$ \\
\hline
\end{tabular}




\begin{tabular}{|c|c|c|}
\hline & & $\begin{array}{l}\text { Linguagens, Educação e Sociedade, } \\
\text { Teresina, n. 9, p.34-40, jan/dez. 2003). } \\
\text { GA: Não encontrado } \\
\text { TG: Professores } \\
\text { TE: Não encontrado } \\
\text { TR: Não encontrado }\end{array}$ \\
\hline $\begin{array}{l}\text { Tesauro de } \\
\text { la UNESCO }\end{array}$ & $\begin{array}{l}\text { Termo: } \\
\text { Afrodescendentes } \\
\text { NE: Não encontrado } \\
\text { GA: Não encontrado } \\
\text { TG: Grupo étnico. } \\
\text { TE: Não encontrado } \\
\text { TR: Mestiço sul- } \\
\text { africano. } \\
\text { Usado para: Afro- } \\
\text { americanos, negro e } \\
\text { pessoas de } \\
\text { ascendência africana. }\end{array}$ & Use: Afrodescendentes \\
\hline \multirow[t]{2}{*}{$\begin{array}{l}\text { Tesauro do } \\
\text { Folclore e } \\
\text { Cultura } \\
\text { Popular } \\
\text { Brasileira }\end{array}$} & \multirow[t]{2}{*}{$\begin{array}{l}\text { Afrodescendentes - } \\
\text { Não encontrado. }\end{array}$} & $\begin{array}{l}\text { Termo: Nego fugido } \\
\text { NE: Folguedo variante do Quilombo, } \\
\text { mantido há pelo menos um século pelos } \\
\text { moradores de Acupe, distrito de Santo } \\
\text { Amaro da Purificação, no Recôncavo } \\
\text { Baiano. Encenaça que recria, } \\
\text { anualmente, tentativa de fuga de escravo, } \\
\text { que é caçado e amarrado, para depois } \\
\text { comprar sua alforria. Os personagens que } \\
\text { representam os negros, quando não estão } \\
\text { correndo ou lutando, ficam em espécie de } \\
\text { dança lenta, ao ritmo da música, que, } \\
\text { segundo pesquisadores, possui ligação } \\
\text { com o candomblé. } \\
\text { GA: Não encontrado } \\
\text { TG: Quilombo (folguedo). } \\
\text { TE: Não encontrado } \\
\text { TR: Não encontrado }\end{array}$ \\
\hline & & $\begin{array}{l}\text { Termo: Nego-bom } \\
\text { NE: Comida, popular no Nordeste, feito à } \\
\text { base de banana, com açúcar e suco de } \\
\text { limão. É geralmente comercializado nas } \\
\text { feiras ou nas pequenas mercearias no } \\
\text { formato de bolinhas enroladas em pedaços } \\
\text { de papel. } \\
\text { GA: Não encontrado } \\
\text { TG: Comida. } \\
\text { TE: Não encontrado } \\
\text { TR: Comércio. }\end{array}$ \\
\hline
\end{tabular}




\begin{tabular}{|c|c|c|}
\hline & & $\begin{array}{l}\text { Termo: Negras da Costa } \\
\text { NE: Bloco formado por homens vestidos } \\
\text { com trajes de baianas. Apresentam-se } \\
\text { com rostos e braços pintados de preto e } \\
\text { dançam ao som de ganzás e reco-reco. Os } \\
\text { personagens "Pai véio" e "Mãe véia" } \\
\text { geralmente participam do folguedo. } \\
\text { GA: Não encontrado } \\
\text { TG: Bloco. } \\
\text { TE: Não encontrado } \\
\text { TR: Carnaval. }\end{array}$ \\
\hline & & $\begin{array}{l}\text { Termo: Negrinho d'água } \\
\text { Use: Caboclo d'água } \\
\text { Termo: Caboclo d'água } \\
\text { NE: Ser mitológico que vive nos rios, tendo } \\
\text { domínio sobre as águas e os peixes. É } \\
\text { baixo, musculoso, cor de cobre, e está } \\
\text { sempre com expressão de raiva. Persegue } \\
\text { ferozmente os pescadores e ribeirinhos, } \\
\text { virando canoas, erguendo ondas, } \\
\text { derrubando as barreiras e afugentando os } \\
\text { peixes. } \\
\text { GA: Não encontrado } \\
\text { TG: Ser mitológico } \\
\text { TE: Não encontrado } \\
\text { TR: Não encontrado }\end{array}$ \\
\hline & & $\begin{array}{l}\text { Termo:Negrinho-do-pastoreiro } \\
\text { NE: Ser mitológico, menino escravo cujo } \\
\text { dono mandou surrar e atirar dentro de um } \\
\text { formigueiro por ter perdido um cavalo que } \\
\text { pastoreava. Resgatado por Nossa } \\
\text { Senhora, ajuda pessoas que tenham } \\
\text { perdido algo. É muito conhecido no Sul do } \\
\text { Brasil. } \\
\text { GA: Não encontrado } \\
\text { TG: Ser mitológico. } \\
\text { TE: Não encontrado } \\
\text { TR: Não encontrado } \\
\text { I78 }\end{array}$ \\
\hline $\begin{array}{l}\text { Tesauro } \\
\text { para Estudos } \\
\text { de Gênero } \\
\text { sobre } \\
\text { Mulheres }\end{array}$ & $\begin{array}{l}\text { Termo: Estudos afro- } \\
\text { brasileiros } \\
\text { NE: Não encontrado } \\
\text { GA: Ciências sociais e } \\
\text { cultura } \\
\quad \text { Educação }\end{array}$ & $\begin{array}{l}\text { Termo: mulheres negras } \\
\text { NE: Não encontrado } \\
\text { GA: Ciências Sociais e Cultura } \\
\text { TG: mulheres } \\
\text { TE: Não encontrado } \\
\text { TR anemia falciforme raça }\end{array}$ \\
\hline
\end{tabular}

Inf. Inf., Londrina, v. 25, n. 1, p. $254-275$, jan./mar. 2020. 


\begin{tabular}{|c|c|}
\hline $\begin{array}{l}\quad \text { História e } \\
\text { mudança social } \\
\text { TG: Não encontrado } \\
\text { TE: Estudos étnicos } \\
\text { TR: Movimento negro }\end{array}$ & $\begin{array}{l}\text { Termo: Mercado negro } \\
\text { GA: Economia e emprego } \\
\text { Lei, governo e políticas públicas }\end{array}$ \\
\hline $\begin{array}{l}\text { Termo: Estudos afro- } \\
\text { brasileiros }\end{array}$ & $\begin{array}{l}\text { TR: Crime organizado } \\
\text { Setor informal }\end{array}$ \\
\hline $\begin{array}{l}\text { NE: Não encontrado } \\
\text { GA: Não encontrado } \\
\text { TG: Não encontrado } \\
\text { TE: Não encontrado } \\
\text { TR: Não encontrado } \\
\end{array}$ & $\begin{array}{l}\text { Termo: Movimento de mulheres negras } \\
\text { NE: Não encontrado } \\
\text { GA: História e mudança social } \\
\text { TG: Movimento de mulheres } \\
\text { TE: Não encontrado } \\
\text { TR: Movimento negro }\end{array}$ \\
\hline $\begin{array}{l}\text { Termo: Religiões afro- } \\
\text { brasileiras } \\
\text { NE: Não encontrado } \\
\text { GA: História e mudança } \\
\text { social } \\
\quad \text { Linguagem, } \\
\text { literatura, religião e } \\
\text { filosofia } \\
\text { TG: Religiões } \\
\text { TE: Candomblé } \\
\quad \text { Umbandismo } \\
\text { TR: Sincretismo } \\
\text { religioso }\end{array}$ & $\begin{array}{l}\text { Termo: Movimento negro } \\
\text { NE: Não encontrado } \\
\text { GA: História e mudança social } \\
\text { TG: Movimento sociais } \\
\text { TR: Estudos afro-brasileiros } \\
\quad \text { Movimento de mulheres negras }\end{array}$ \\
\hline
\end{tabular}

Fonte: Dados da pesquisa (2018).

Como mencionado, dos sete tesauros pesquisados, apenas quatro retornaram resultados à pesquisa. Desses quatro, 18 termos foram listados por se adequarem a investigação proposta. Dentre esses 18,7 termos apresentam notas explicativas. De forma ampla, os termos apresentaram a estrutura parcial de relações hierárquicas e associativas. Tesauros são compostos por descritores semanticamente relacionados, formados pelo cruzamento lógico e hierárquico de seus conceitos, assim sua estrutura se baseia não só em conceitualizações, mas também nos relacionamentos entre seus termos (CARLAN, 2010). Os tesauros são sistemas usados em diversos domínios e com a função de organizar e representar o conhecimento registrado em áreas 
especializadas (LIMA; KROEFF; RIBEIRO JUNIOR, 2014). Com relação à estrutura dos termos, percebemos que a ausência de notas explicativas explicitando o significado e/ou contexto dos termos limitam sua interpretação e entendimento. Os tesauros da Ciência da Informação, da Justiça Militar da União e de Objetos do Patrimônio Cultural nos Museus Brasileiros, não retornaram resultados à pesquisa. Assim, diante de um cenário social que se compreende a necessidade de reivindicar direitos à representatividade das ditas minorias sociais, permitindo avanços quanto a compreensão de que as práticas de preconceitos e discriminação negativa possam ser combatidas com informação e com a construção de memórias sociais e na valorização da diversidade humana (SANTANA; OLIVEIRA; LIMA, 2016), pode-se inferir que tais áreas ainda não se atentaram às necessidades particulares de importância na representatividade terminológica da população negra. Sobretudo na área da Ciência da Informação, a ausência de termos relacionados à população negra demonstra a imperícia da área em contemplar diferentes áreas do saber e contribuir na busca de uma sociedade mais igualitária (LIMA; KROEFF; RIBEIRO JUNIOR, 2014), "uma vez que a ciência da informação trata de um campo interdisciplinar que pode contribuir para a compreensão das relações entre informação, raça e etnia, em função da redução do preconceito racial, discriminações e racismos" (OLIVEIRA; AQUINO, 2012, p. 1).

O Tesauro de Objetos do Patrimônio Cultural nos Museus Brasileiros, que abarca um conjunto terminológico especifíco sobre objetos, necessita ser utilizado em conjunto com outro tesauro que permita a descrição das etnias, povos, grupos culturais, etc., que produziram esses objetos.

O Tesauro Brasileiro da Educação aponta em um de seus resultados o termo "aluno negro", subordinado ao termo geral "alunos" e termo relacionado "condições biopsíquicas" (em que ocorrem também termos como "aluno adulto", "aluno com necessidades especiais", entre outros) que, por sua vez, é subordinado ao termo "alunos". A condição biopsíquica está "relacionada com o que ocorre no âmbito mental e comportamental de uma pessoa: fenômenos psíquicos" (DIClO, 2009, p. 1). Pressupomos que essa estrutura terminológica representa ações que a população negra vem passando, por décadas, como por 
exemplo, desigualdade, exploração do homem pelo homem e preconceitos, ainda muito presentes no âmbito escolar e, portanto, com produção informacional sobre o assunto. E vem lutando para "assegurar para si a liberdade, a segurança e a igualdade social" (SOUSA; ALBUQUERQUE, 2015, p. 4).

Como já citado anteriormente, tesauros são sistemas que geralmente atendem a uma área específica do conhecimento. Diante dessa perspectiva, o Tesauro do Folclore e Cultura Popular Brasileira, apesar de apresentar termos como "nego fugido", "nego-bom", "negras da costa", "negrinho d'água" e "negrinho-do-pastoreiro" não pode ser criticado quanto ao emprego de tais termos, uma vez que os mesmos se encontram inseridos no contexto folclórico. Antes disso, a crítica ou mesmo reflexão, nesse caso, conduz no sentido de constatar a forte incidência de termos que relacionam a população negra com aspectos folclóricos. Outrossim, mesmo não sendo objeto de estudo do presente trabalho, foi realizado nesse tesauro a busca por termos que remetessem à população branca e não se obteve resultados, o que reforça a concepção de que a população negra está associada à aspectos relacionados ao folclore e, de certa forma, pejorativos.

Ao realizar a busca no dicionário, verifica-se que o termo folclore remete a um conjunto de tradições, lendas e costumes populares, associados à invenção, mentira e lenda, que são preservados e passados de uma geração para outra (DIClO, 2009). O que comuna na compreensão de que a visão de conhecimento se estrutura a partir da concepção europeia, branca e elitista e que relega ao negro condições de dominação cultural e ocultamento da sua identidade e da memória. Dado que, via de regra, sua imagem vem sendo representada no imaginário social de forma estereotipada e folclórica.

O Tesauro para Estudos de Gênero sobre Mulheres apresenta o termo "mercado negro" vinculado ao grupo de assunto economia e emprego. A expressão 'mercado negro', de acordo com Méndez (2016, p. 3), é uma das "expressões em que a palavra 'negro' representa algo pejorativo, prejudicial, ilegal", portanto, esse termo entra em desuso já que é extremamente ofensivo e racista. 
Os resultados obtidos debatidos junto a literatura estudada mostraram que as atividades da ORC perpassam um fazer técnico e possuem uma dimensão social e ética bastante perceptível. Isso se deve a interpretação de que o conhecimento se constrói socialmente e que os sistemas de organização traduzem a realidade em que estão inseridos, por isso, são permeados a partir de uma visão particular de mundo e motivadas por pré-concepções e preconceitos (MAI, 2004). Os tesauros analisados demonstram a existência do fortalecimento da imagem do negro associada a termos pejorativos em sua representação. Por outro lado, os pesquisadores da área de OC tem repensado e trazido para discussão processos de representação mais plurais e igualitários, com posicionamento ético e reflexivo e é esse o nosso convite com essa breve análise.

\section{CONSIDERAÇÕES FINAIS}

Os Sistemas de Organização do Conhecimento são ferramentas utilizadas para a recuperação das informações, portanto, espera-se que os termos sejam capazes de atender as necessidades informacionais dos usuários. Contudo, a organização do conhecimento reflete a realidade da sociedade na qual está inserida e seus sistemas, que são construídos a partir de uma visão particular, carregados de desvios de adequação terminológica, sobretudo a despeito das minorias sociais.

Frente à uma sociedade que brada por mais igualdade $\mathrm{e}$ representatividade de classes, é indispensável que a área da organização do conhecimento reflita sobre o seu próprio fazer, aprimorando em suas práticas à capacidade de representar informação sobre diversas perspectivas de demandas informacionais. Sobretudo em relação a representação terminológica das informações relacionadas a população negra, acredita-se que a adequada representação terminológica possa contribuir à afirmação positiva de sua identidade, reconhecimento da diversidade, construção de sua memória e quebra de preconceitos, ao passo que desconsiderar essa necessidade, pode contribuir à perpetuação do estigma do negro escravizado, subjugado e invisibilizado. 
A literatura da área aponta para avanços, mesmo que tímidos, quanto a reflexão do posicionamento ético e da responsabilidade social que permeia as práticas da ORC. E espera-se que o presente estudo possa contribuir, de certa maneira, a novos estudos na temática, buscando construir cada vez mais uma organização do conhecimento mais plural e multicultural. Visto que o posicionamento ético das práticas cotidianas das atividades da organização do conhecimento, bem como a compreensão de sua dimensão social se configura como uma grande incitação à área da organização e representação do conhecimento.

\section{REFERÊNCIAS}

AQUINO, M. A.; SANTANA, V. A. Práticas de organização e representação da informação étnico-racial em bibliotecas universitárias: necessidade de preservação a memória dos negros. Revista Ibero-americana de Ciência da Informação, Brasília, v. 6, n. 2, p. 17-36, ago./dez. 2013. Disponível em: http://eprints.rclis.org/23224/1/Pr\%C3\%A1ticas\%20de\%20organiza\%C3\%A7\% C3\%A30\%20e\%20representa\%C3\%A7\%C3\%A30\%20da\%20informa\%C3\%A7 \%C3\%A30\%20\%C3\%A9tnico-racial.pdf. Acesso em: 15 ago. 2018.

BARITÉ, M. Organización del conocimiento: un nuevo marco teórico-conceptual en Bibliotecología y Documentación. In: CARRARA, K. (org.). Educação, Universidade e Pesquisa. Marília: UNESP, 2001. p. 35-60.

BRASCHER, M.; CARLAN, E. Sistemas de Organização do Conhecimento: antigas e novas linguagens. In: ROBREDO, J.; BRASCHER, M.(Orgs.).

Passeios pelo bosque da informação: estudos sobre representação $e$ organização da informação e do conhecimento. Brasília: IBICT, 2010. p. 147176.

CAFÉ, L.; BRÄSCHER, M. Organização do conhecimento: teorias semânticas como base para estudo e representação de conceitos. Ciência da Informação, Londrina, v. 16, n. 3, p. 25-51, jan./jun. 2011. Disponível em:

http://www.uel.br/revistas/uel/index.php/informacao/article/view/10388. Acesso em: 04 dez. 2018.

CARDOSO, F.; PINTO, M. S. Apontamentos Contemporâneos sobre a questão racial e a atuação bibliotecária. In: SILVA, F. C. G.; LIMA, G. S. (orgs.).

Bibliotecári@s Negr@s: ação, pesquisa e atuação política. Florianópolis: ACB, 2018, p. 39-88.

CARDOSO, F. C. A biblioteca pública na (re)construção da identidade negra. 2011. Dissertação (Mestrado em Ciência da Informação) - Universidade 
Federal Fluminense, Niterói, 2011. Disponível em:

https://pt.scribd.com/document/323989207/A-Biblioteca-Publica-Na-ReConstrucao-Da-Identidade-Negra-Prof-Francilene-Do-Carmo-Cardoso. Acesso em: 22 set. 2017.

CARLAN, E. Sistemas de organização do conhecimento: uma reflexão no contexto da Ciência da Informação. 2010. Dissertação (Mestrado em Ciência da Informação) - Universidade de Brasília, Brasília (DF), 2010. Disponível em: http://repositorio.unb.br/bitstream/10482/7465/1/2010_ElianaCarlan.pdf. Acesso em: 04 abr. 2018.

CARLAN, E.; MEDEIROS, M. B. B. Sistemas de Organização do Conhecimento na visão da Ciência da Informação. Revista Ibero-americana de Ciência da Informação, Brasília, v. 4, n. 2, p. 53-73, ago. 2011. Disponível em: http://periodicos.unb.br/index.php/RICl/article/view/6209/5102. Acesso em: 12 nov. 2018.

CERVO, A. L.; BERVIAN, P. A. Metodologia Científica. 5. ed. São Paulo: Person Prentice Hall, 2002.

CINTRA, A. M. M.; TÁLAMO, M. F. G.M.; LARA, M. L. G. de; KOBASHI, N. Y. Para entender as linguagens documentárias. São Paulo: Polis, 2002.

DAHLBERG, I. Teoria do conceito. Ciência da Informação, Rio de Janeiro, v. 7, n. 2, p. 101-107, 1978.

DAHLBERG, I. Knowledge Organization: a New Science?. Knowledge Organization, [S. I], v. 33, n. 1, p.11-19, 2006.

DICIO. Psíquico. 2009. Disponível em: https://www.dicio.com.br/psiquico/. Acesso em: 15 out. 2018.

ESTEBAN NAVARRO, M. A. El marco disciplinar de los lenguajes documentales: la Organización del Conocimiento y las ciencias sociales. Scire, Zaragoza (ESP), v. 2, n. 1, p.93-107, jun. 1996. Disponível em:

https://www.ibersid.eu/ojs/index.php/scire/article/view/1051/1033. Acesso em: 25 abr. 2018.

GUIMARÃES, J. A. C.; PINHO, F. A. Aspectos éticos em organização e representação do conhecimento (O.R.C.). In: ENCONTRO NACIONAL DE PESQUISA EM CIÊNCIA DA INFORMAÇÃO, 7., 2006, Marília. Anais [...]. Marília: UNESP, 2006. p. 1-14.

INSTITUTO BRASILEIRO DE INFORMAÇÃO EM CIÊNCIA E TECNOLOGIA. Diretrizes para elaboração de tesauros monolíngues. Rio de Janeiro: IBICT, 1984.

INTERNATIONAL ORGANIZATION FOR STANDARDIZATION. ISO 25964-1. 2011. Disponível em: https://www.iso.org/standard/53657.html. Acesso em: 14 out. 2018. 
LAAN, R. H. V. D.; FERREIRA, G. I. S. Tesauros e terminologias. In: CONGRESSO BRASILEIRO DE BIBLIOTECONOMIA E DOCUMENTAÇÃO, 19., 2000, Porto Alegre. Anais [...]. Porto Alegre: CBBD, 2000. p. 1-12.

LIMA, J. L. O.; ALVARES, L. Organização e Representação da Informação e do Conhecimento: In: ALVARES, L. (org.). Organização da informação e do conhecimento: conceitos, subsídios interdisciplinares e aplicações. São Paulo: B4 Editores, 2012, p.21-48.

LIMA, G. S.; KROEFF, M. S.; RIBEIRO JUNIOR, D. I. Tesauro afro-brasileiro: uso estratégico para organização e recuperação de informação. In: ENCONTRO NACIONAL DE PESQUISA EM CIÊNCIA DA INFORMAÇÃO, 15. 2014, Belo Horizonte. Anais [...]. Belo Horizonte: ECI, UFMG, 2014.

MAI, J. -E. Classification in context: relativity, reality, and representation. Knowledge Organization, Würzburg, v. 31, n. 1, p. 39-48, 2004. Disponível em: http://jenserikmai.info/Papers/2004_ClassificationInContext.pdf. Acesso em: 13 set. 2018.

MARTÍNEZ-ÁVILA, D.; GUIMARÃES, J. A. C.; PINHO, F. A.; FOX, M. J. The representation of ethics and Knowledge Organization in the WoS and LISTA Databases. Knowledge Organization, [s. I.], v. 42, n. 5, p. 269-275, jul. 2015. Disponível em: https://repositorio.unesp.br/bitstream/handle/11449/190649/2s2.0-84956670254. pdf?sequence=1\&isAllowed=y. Acesso em: 27 mar. 2020.

MÉNDEZ, C. 18 expressões racistas que você usa sem saber. 2016. Disponível em: https://www.geledes.org.br/18-expressoes-racistas-que-voceusa-sem-saber/. Acesso em: 15 out. 2018.

MIRANDA, M. L. C. A Organização do conhecimento e seus paradigmas científicos: uma abordagem epistemológica. Informare - Cad.prog.pósgrad.ci.inf, Rio de Janeiro, v. 5, n. 2, p. 64-77, jul./dez. 1999. Disponível em: http://www.brapci.inf.br/index.php/res/v/41854\#. Acesso: 07 abr. 2018.

MIRANDA, M. L. C. A Organização do Etnoconhecimento: a representação do conhecimento afrodescente em religião na CDD. In: ENCONTRO NACIONAL DE PESQUISA EM CIÊNCIA DA INFORMAÇÃO, 8., 2007, Salvador. Anais [...]. Salvador: PPGCI, UFBA, 2007.

\section{NATIONAL INFORMATION STANDARDS ORGANIZATION. ANSI/NISO}

Z39.19-2005. 2005. Disponível em: https://groups.niso.org/apps/group_public/download.php/12591/z39-192005r2010.pdf. Acesso em: 14 out. 2018.

OLIVEIRA, H. P. C.; AQUINO, M. A. O conceito de informação etnicorracial na Ciência da Informação. Liinc em Revista, Rio de Janeiro, v. 8, n. 2, p. 466492, set. 2012. Disponível em: http://www.brapci.inf.br/index.php/res/v/90559. Acesso em: 23 mar. 2018. 
OLSON, H. A. The power to name: locating the limits of subject representation in libraries. Dordrecht: Kluwer Academic Publishers, 2002.

ORTOLAN, L. P. V.; SILVA, M. F. da; ALVES, R. C. V.; MARTÍNEZ-ÁVILA, D. As temáticas sobre o negro na Ciência da Informação brasileira. Biblionline, João Pessoa, v. 13, n. 3, p. 14-29, jul. 2017. Disponível em: http://www.periodicos.ufpb.br/ojs2/index.php/biblio/article/view/35715. Acesso em: 10 ago. 2018.

PINHEIRO, L. V. R.; FERREZ, H. D. Tesauro Brasileiro da Ciência da Informação. Brasília: IBICT, 2014. 384 p. Disponível em: http://sitehistorico.ibict.br/publicacoes-e-institucionais/tesauro-brasileiro-deciencia-da-informacao-

1/copy_of_TESAUROCOMPLETOFINALCOMCAPA24102014.pdf. Acesso em: 13 nov. 2018.

\section{PINHO, F. A. Aspectos éticos em representação do conhecimento em} temáticas relativas à homossexualidade masculina: uma análise da precisão em linguagens de indexação brasileiras. 2010. Tese (Doutorado em Ciência da Informação) - Universidade Estadual Paulista, Marília, 2010. Disponível em: https://www.marilia.unesp.br/Home/PosGraduacao/Cienciadalnformacao/Dissertacoes/pinho_fa_do_mar.pdf. Acesso em: 24 abr. 2018.

PINHO, F. A.; NASCIMENTO, F. A.; MARINHO, A. C. M. A contribuição da Organização do Conhecimento para a memória da homoafetividade. In: ENCONTRO NACIONAL DE PESQUISA EM CIÊNCIA DA INFORMAÇÃO, 14. 2013, Florianópolis. Anais [...]. Florianópolis: UFSC, 2013. p. 1-20.

SALES, R.; CAFÉ, L. Diferenças entre Tesauros e Ontologias. Perspectivas em Ciência da Informação, Belo Horizonte, v. 14, n. 1, p. 99-116, jan./abr. 2009. Disponível em: http://portaldeperiodicos.eci.ufmg.br/index.php/pci/article/view/646. Acesso: 05 mar. 2018.

SANTANA, S. R.; OLIVEIRA, H. P. C.; LIMA, I. F. Informação étnico-racial na memória da produção científica do grupo Nepiere. In: ENCONTRO NACIONAL DE PESQUISA EM CIÊNCIA DA INFORMAÇÃO, 17., 2016, Salvador. Anais [...]. Salvador: PPGCI, UFBA, 2016.

SOUSA, M. A.; ALBUQUERQUE, M. E. B. C. Informação étnico-racial: proposta de glossário sob a égide da semântica discursiva. In: ENCONTRO NACIONAL DE PESQUISA EM CIÊNCIA DA INFORMAÇÃO, 16., 2015, João Pessoa.

Anais [...]. João Pessoa: UFPB, 2015. p. 1 - 18.

\section{TERMINOLOGICAL REPRESENTATION OF THE BLACK POPULATION IN TESAUROS}




\begin{abstract}
Introduction: The present work investigates the terminological representation on the black population in thesauri of different areas of knowledge. The theoretical reference is focused on the interpretation of the social dimension that encompasses the practices of knowledge organization. The respondents from the $\mathrm{OC}$ area have rethought and brought to discussion more pluralistic and egalitarian representation processes, with ethical and reflexive positioning. Aims: To analyze the conceptual relationships attributed to the terms 'black' and 'Afro-Brazilian' in thesauri of different areas of knowledge. Methodology: The research is characterized as exploratory and bibliographical. The terms "Afro-Brazilian" and "Black" were analyzed in the following thesauri: Information Science, Education, Gender Studies on Women, Folklore and Popular Culture, Military Justice of the Union, Objects of Cultural Heritage in Brazilian Museums, and UNESCO. Results: It was verified that the analyzed thesauri strengthen the image of the black associated with pejorative terms in their representations. Conclusions: SOCs are tools used for information retrieval, however, it is clear that the structure of these instruments reflects the reality in which these systems are inserted. It is noticed that researchers in the area of knowledge organization have rethought and brought discussions with an ethical and reflective positioning.
\end{abstract}

Descriptors: Organization System. Thesauri. Black population.

\title{
REPRESENTACIÓN TERMINOLÓGICA DE LA POBLACIÓN NEGRA EN TESAUROS
}

\begin{abstract}
RESUMEN
Introducción: El presente trabajo investiga la representación terminológica sobre la población negra en tesauros de diferentes áreas del conocimiento. El referencial teórico está orientado a la interpretación de la dimensión social que abarca las prácticas de la organización del conocimiento. Los investigadores del área de OC han repensado y traído para discusión procesos de representación más plurales e igualitarios, con posicionamiento ético y reflexivo. Objetivos: Se pretende analizar cuáles son las relaciones conceptuales atribuidas a los términos 'negro' y 'afro-brasileño' en tesauros de diferentes áreas del conocimiento. Metodología: La investigación está caracterizada como exploratoria y bibliográfica. Se analizaron los términos "afro-brasileño" y "negro" en los siguientes tesauros: Ciencia de la Información, Educación, Estudios de Género sobre Mujeres, Folclore y Cultura Popular, Justicia Militar de la Unión, Objetos del Patrimonio Cultural en los Museos Brasileños, y UNESCO. Resultados: Se constató que los tesauros analizados fortalecen la imagen del negro asociada a términos peyorativos en sus representaciones. Conclusiones: Ios SOC son solo herramientas utilizadas para la recuperación de información, continuidad y darse cuenta de que al comienzo de estos instrumentos, reflejan una realidad en la que se insertan estos sistemas. Quizás los investigadores en el área de conocimiento de la organización han repensado y esbozado las discusiones con una postura ética y reflexiva.
\end{abstract}

Descriptores: Sistema de Organización del Conocimiento. Tesauros. Población Negra.

Recebido em: 12/10/2018

Aceito em: 10/10/2019 